\title{
Meninas High-Tech
}

\author{
Stephany Coelho \\ Instituto Federal do Rio Grande do Sul - IFRS \\ Feliz \\ stecoelho10@gmail.com \\ Maria Julia Portal Weissheimer \\ Instituto Federal do Rio Grande do Sul - IFRS \\ Feliz \\ majupw2002@gmail.com \\ Taiane de Oliveria Puccio \\ Instituto Federal do Rio Grande do Sul - IFRS \\ Feliz \\ tai.o.puccio@gmail.com \\ Nicole Marques da Silva \\ Instituto Federal do Rio Grande do Sul - IFRS \\ Feliz \\ marquesnicole04@gmail.com
}

\author{
Leandro Von Borstel Assmann \\ Instituto Federal do Rio Grande do Sul - IFRS \\ Feliz \\ leandroassmann14@gmail.com \\ Vanessa Petró \\ Instituto Federal do Rio Grande do Sul - IFRS \\ Feliz \\ vanessa.petro@feliz.ifrs.edu.br \\ Vinicius Hartmann Ferreira \\ Instituto Federal do Rio Grande do Sul - IFRS \\ Feliz \\ vinicius.ferreira@feliz.ifrs.edu.br
}

\begin{abstract}
Inequality and discrimination according to gender have been debated for decades, gender equality is among the Millennium Development Goals, proposed by the UN. Numerous barriers are still faced in the academic and work world, with regard to the participation of women in science and technology. The Girls High-Tech project was created in line with the "Digital Girls" program, proposed by the Brazilian Computer Society, working within the scope of the IFRS Happy Campus and schools located in the region. The main objective of the project is to promote reflections and actions on female participation in the area of Information Technology (IT), seeking to encourage the performance of girls in this area and problematizing gender inequalities.
\end{abstract}

\section{KEYWORDS}

Tecnologia da informação, Gênero, Desigualdade

\section{Introdução}

As mulheres, ao longo da história, têm encontrado dificuldades de se inserirem no campo da ciência e da tecnologia. Estudos realizados no Brasil [1] abordam a desigualdade de gênero na área de Tecnologia da Informação (TI). A pesquisa aponta uma queda no percentual das mulheres matriculadas nos cursos da área da Computação, sendo um percentual de 24\%, em 2001, e o percentual de 2017 igual a 14\%. Analisados o número de ingressantes e concluintes, em 2017, o número de alunas ingressantes representava $13,8 \%$ do total, um número pequeno quando comparado ao ano de 2008, quando o percentual chegou ao seu valor histórico máximo de $40 \%$. Neste mesmo panorama o número de alunas concluintes vem diminuindo desde 2001, quando representava $31,8 \%$, até chegar em 2017 representando apenas $15,4 \%$. Os dados indicam que a presença de mulheres nos cursos é cada vez menor.

Entre as razões apontadas para a sub-representação das mulheres na área podemos encontrar, dentre outras [2]: falta de preparação científica dos professores, má atitude das mulheres em relação à ciência como consequência de falta de experiências positivas desde a infância, ausência de modelos femininos a serem seguidos nas áreas de ciências e engenharia, currículos irrelevantes para as mulheres, pedagogia de ensino de ciências em favor de estudantes do sexo masculino, "ambientes frios" para as mulheres nas aulas de ciências; pressão cultural sobre as mulheres para se ajustarem aos papeis tradicionais de gênero e uma visão inerente do mundo masculino na epistemologia científica.

A questão de gênero na área da TI não é apenas uma questão numérica ou de sub-representação. Também é de suma importância a discussão relacionada às formas de discriminação de gênero que ocorrem nessa área [3, 4 ].

Com o intuito de problematizar as desigualdades de gênero e a falta de representatividade feminina na área vem sendo desenvolvidas inúmeras iniciativas, sobretudo a partir do programa Meninas Digitais, criado pela Sociedade Brasileira de Computação (SBS), cuja atuação enfoca a aproximação de meninas do ensino básico à área de Computação. $\mathrm{O}$ projeto de extensão Meninas High-Tech se junta a essas ações, tendo como objetivo promover reflexões e ações sobre a participação feminina na ciência e na tecnologia, buscando incentivar a atuação das meninas nessa área. 


\section{Materiais e metodologia}

As ações planejadas no âmbito do projeto de extensão Meninas High-Tech foram desencadeadas a partir de estudos sobre a temática de gênero que ocorreram na disciplina de Sociologia de um Curso Técnico em Informática Integrado ao Ensino Médio. A partir do trabalho realizado em sala de aula, estudantes se interessaram pela temática e foi formado um grupo inicial para o planejamento de ações que poderiam ser desenvolvidas visando abordar a questão de gênero nesta área de TI.

Portanto, o planejamento das atividades é embasado nas experiências e na percepção sobre as demandas manifestadas por discentes. $\mathrm{O}$ projeto também se preocupa em fomentar o protagonismo de estudantes na construção das atividades, considerando a importância dessas vivências para a sua formação pessoal e profissional e atuação social. Assim, discentes, através das suas experiências, e por serem oriundos(as) de diferentes escolas e cidades e vivenciarem esses locais são capazes de trazer parte das demandas desses espaços para serem contempladas nas ações propostas.

As atividades propostas no âmbito do projeto foram desenvolvidas com a comunidade interna do Campus Feliz do IFRS, sobretudo da área de TI e também envolvendo a comunidade externa à instituição,pois o relato aqui apresentado é de um projeto de extensão, cujo objetivo é promover reflexões e ações sobre a participação feminina na área de TI, buscando incentivar a atuação das meninas nessa área e problematizando as desigualdades de gênero. Considerando o contexto de pandemia enfrentado no ano de 2020, as ações foram abertas ao público e transmitidas pela internet.

Entre as ações propostas esteve a criação de um perfil para o projeto no Instagram, onde são desenvolvidas duas principais atividades: a) a divulgação da história de mulheres que contribuíram para a área da Informática e b) dicas de filmes que abordem o protagonismo feminino e a questão das diversidades, sobretudo na área de TI. Além disso, ocorreu um conjunto de lives realizadas em comemoração ao Ada Lovelace Day. As atividades do projeto são desenvolvidas pelas(os) estudantes envolvidas(os).

\section{Ações desenvolvidas}

As ações desenvolvidas pelo projeto de extensão Meninas HighTech começaram no início de 2020. O público participante das ações, além dos próprios estudantes da instituição, são escolas de ensino fundamental e médio, além do público em geral, considerando que as atividades ocorreram de modo online.

A primeira atividade ocorreu de forma presencial, sendo ela a realização do "Cine-Debate" (Figura 1), o qual buscou discutir as relações entre gênero, ciência, tecnologia e trabalho, com a exibição do filme "Estrelas Além do Tempo". Após a exibição do filme, convidadas de diferentes áreas do conhecimento debateram sobre o tema. Entre os objetivos da atividade estavam celebrar o dia 8 de março como uma data para refletir sobre o espaço ocupado pelas mulheres na academia e no mundo do trabalho e fomentar discussões acerca da representatividade da mulher na ciência e na tecnologia. A atividade contou com 255 participantes, incluindo público interno e estudantes de escolas da região.

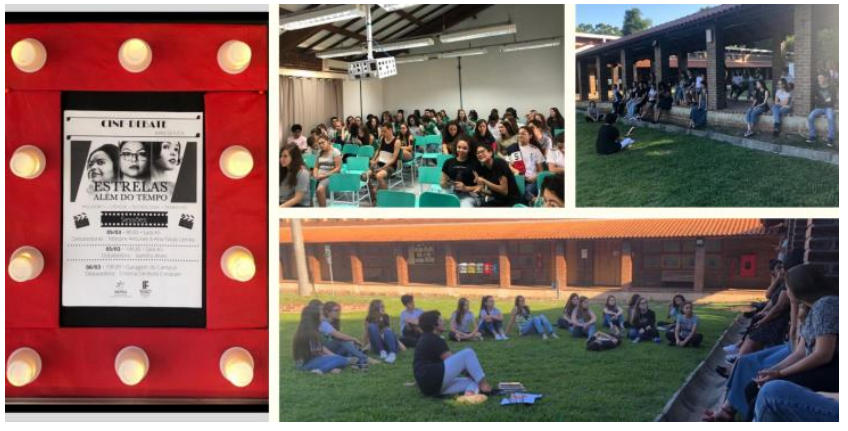

Figura 1: Cine-debate. Fonte: própria (2020)

Com o início da pandemia e o cancelamento de atividades presenciais, houve a necessidade de dar continuidade ao projeto de forma remota, por isso, foi criada uma página do projeto no Instagram (Figura 2), onde todas as postagens abordam temas relacionados à área de TI e questões de gênero, as mesmas incluem: textos que falam sobre a vida e as contribuições de mulheres importantes para a história da computação; "CineDicas", dicas de filmes e documentários sobre gênero; e lives, que discutem temas atuais na área da computação.

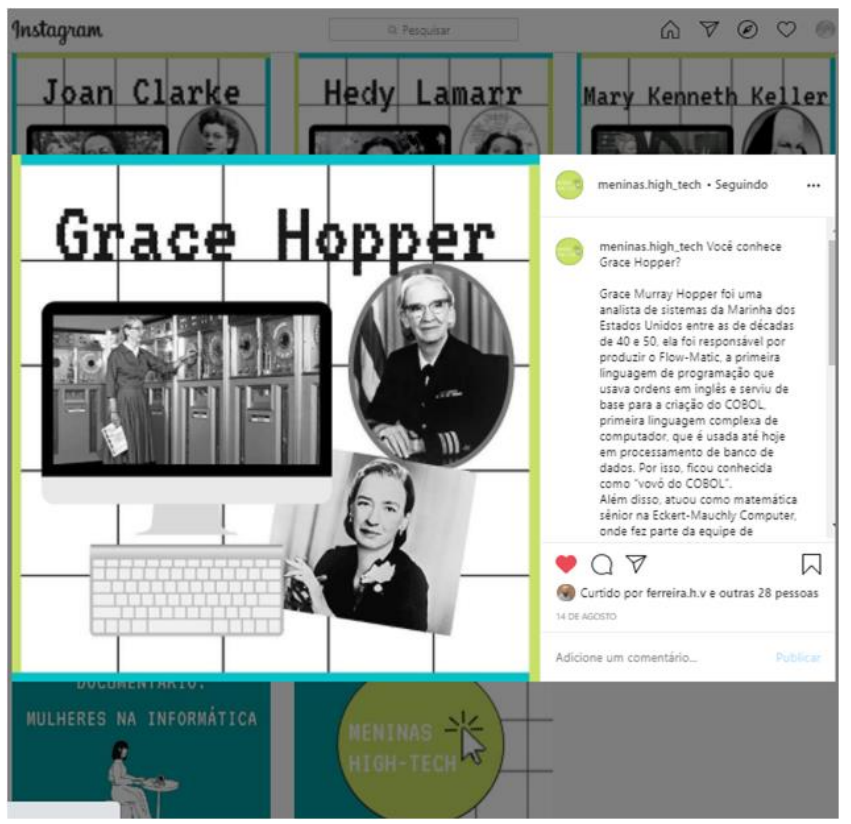

Figura 2: Página do projeto no Instagram. Fonte: própria (2020)

Em comemoração ao Ada Lovelace Day no mês de outubro foi realizado um conjunto de lives abordando temas relacionados à tecnologia e gênero. Uma das lives ocorreu com uma representante do programa Meninas Digitais da SBC, cujo objetivo foi apresentar o programa e discutir a participação das mulheres na área de TI. Duas lives consistiram em entrevistas com mulheres profissionais na área de Informática, resgatando suas trajetórias e uma das lives discutiu inteligência artificial. Um dos objetivos centrais das comemorações do Ada Lovelace Day 
está ligado à necessidade de visibilidade das profissionais mulheres na área de TI.

As atividade desenvolvidas, por serem todas de modo online, estão disponíveis para toda a comunidade interna e externa, com enfoque para pessoas interessadas nos temas de gênero e tecnologia. No momento da realização das live a participação do público foi considerada baixa, em torno de 15 pessoas assistindo simultaneamente. Entretanto, a possibilidade de deixar as gravações disponíveis nos canais de comunicação do projeto (YouTube e Instagram) amplia significativamente o número de acessos, ampliando o alcance das ações. Mas, isso também sinaliza para a necessidade do projeto promover ações voltadas para públicos específicos, tais como turmas de estudantes das escolas da região, mesmo que de forma remota ainda, para ampliar o alcance das ações e ter um recorte melhor do público.

\section{Considerações Finais}

Este artigo apresentou um relato das atividades desenvolvidas no âmbito do projeto de extensão Meninas High-tech. Em decorrência do cenário mundial da pandemia de Covid-19, as atividades precisaram ser reorganizadas para serem desenvolvidas no formato remoto. Entretanto, isso não inviabilizou a participação e as discussões sobre o tema, criando-se, assim, um espaço para reflexão sobre a questão de gênero na área de TI, inclusive na própria instituição.

Quando for possível o retorno de atividades presenciais, o projeto terá continuidade com atividades relacionadas ao tema nas escolas de Educação Básica, tais como: oficinas interativas, que visam estimular o aprendizado de TI por meninas ainda no Ensino Fundamental; e a continuação dos "Cine-Debates", de forma presencial. Mas, mesmo com os imprevistos que ocorreram, as novas ações criadas já mostraram-se exitosas, pois auxiliaram para que a equipe do projeto pudesse conhecer melhor o público atendido, além de divulgá-lo por meio do uso das redes sociais, e estas também são ótimas ferramentas para promover as discussões propostas pelo projeto, discussões essas que até então não eram feitas na região.

\section{ACKNOWLEDGMENTS}

Agradecemos ao IFRS pelo apoio financeiro, proporcionando bolsas ao projeto.

\section{REFERÊNCIAS}

[1] SBC. Educação Superior em Computação Estatísticas, 2017. URLhttp://www.sbc.org.br/documentos-da-sbc/summary/133-estatisticas/.

[2] Sapna Cheryan, Sianna A. Ziegler, Amanda K. Montoya and Lily Jiang. Why are some STEM fields more gender balanced than others? Psychological Bulletin, 143(1): 1-35, 2017. doi: https://doi.org/10.1037/bul0000052.

[3] Bárbara Castro. 2013. Os gargalos para o ingresso e a permanência das mulheres no mercado de TI no Brasil. In XII Conferência Regional sobre la Mujer de La America Latina y Caribe, Santo Domingo. Cepal, 15-18.

[4] Vanessa Petró. 2020. Percursos escolares e profissionais femininos na área de Tecnologia da Informação. In $44^{\circ}$ Encontro Anual da Anpocs,São Paulo, December, 1-11. 